\title{
ФИКСАЦИЯ ОБСТАНОВКИ МЕСТА ДОРОЖНО-ТРАНСПОРТНОГО ПРОИСШЕСТВИЯ С ПОМОЩЬЮ БЕСПИЛОТНОГО ЛЕТАТЕЛЬНОГО АППАРАТА
}

\section{Александр Игнатьевич Недобитков}

Восточно-Казахстанский технический университет, 070014, Казахстан, г. Усть-Каменогорск, ул. Серикбаева, 19, кандидат технических наук, старший научный сотрудник Центра превосходства Veritas, тел. (87232)54-14-88, e-mail: a.nedobitkov@mail.ru

\section{Андрей Иванович Охотенко}

Восточно-Казахстанский технический университет, 070014, Казахстан, г. Усть-Каменогорск, ул. Серикбаева, 19, инженер-исследователь, тел. (87232)54-14-88, e-mail: aohotenko @mail.ru

В статье приведены описание, недостатки и преимущества съемки с помощью беспилотного летательного аппарата. Приведены конкретные примеры использования беспилотного летательного аппарата при осмотре места дорожно-транспортного происшествия. Показаны некорректные случаи использования беспилотного летательного аппарата. Продемонстрировано создание ортофотоплана и построение на его основе размерной цепи участка дорожно-транспортного происшествия. Подчеркнута актуальность использования беспилотного летательного аппарата при осмотре мест чрезвычайных ситуаций. Дана ссылка на точность получаемых цифровых моделей, а также их соответствие требованиям нормативных документов. Подтверждено, что использование беспилотного летательного аппарата для осмотра места дорожнотранспортного происшествия не только сокращает время следственного действия, снижает вероятность заторов на улично-дорожной сети, но и дает более точные исходные данные для последующего проведения автотехнической экспертизы.

Ключевые слова: фотограмметрия, беспилотный летательный аппарат, дорожно-транспортное происшествие, цифровая модель, автотехническая экспертиза, ортофотоплан

\section{UNMANNED AERIVAL VEHICLE RECORDINGS OF THE TRAFFIC ACCIDENT SCENE}

\section{Alexander I. Nedobitkov}

D. Serikbayev East Kazakhstan Technical University, 19, Serikbayev St., Ust-Kamenogorsk, 070002, Kazakhstan, Ph. D., Senior Research of Priority Development Center Veritas, phone: (87232)54-14-88, e-mail: a.nedobitkov@mail.ru

\section{Andrey I. Okhotenko}

D. Serikbayev East Kazakhstan Technical University, 19, Serikbayev St., Ust-Kamenogorsk, 070002, Kazakhstan, Research Engineer of Priority Development Center Veritas, phone: (87232)54-14-88, e-mail: aohotenko@mail.ru

Description, disadvantages, and advantages of the unmanned aerial vehicle recording result in this article. Specific unmanned aerial vehicle application examples of traffic accident scene inspecting are given. The article shows the inaccurate unmanned aerial vehicle application cases and demonstrates the orthophoto map creation and the traffic accident scene dimensional chain construction on its basis. The emphasis falls on the unmanned aerial vehicle application's relevance in emergencies. There are also references for unmanned aerial vehicle in making accurate digital models, as well as their compliance with the regulatory document requirements. unmanned aerial vehicle application is confirmed to inspect the traffic accident scene that not only reduces the investigation time and the likelihood of congestion on the road system but also provides more accurate initial data for subsequent car technical expertise. 
Keywords: photogrammetry, unmanned aerial vehicle, traffic accident, digital model, technical expertise, orthophoto map

\section{Введение}

В работе [1] отмечается, что фотограмметрия позволяет определить по снимкам исследуемого объекта его форму, размеры и пространственное положение в заданной системе координат, а также его площадь, объём, различные сечения на момент съёмки и изменения их величин через заданный интервал времени. В связи с этим, фотограмметрию используют в различных областях науки и техники, в том числе для фиксации и составления схемы дорожно-транспортного происшествия или места преступления [1].

Автором [2] показано, что технологию осмотра места дорожно-транспортного происшествия с определенной степенью условности можно разделить на два этапа. Первый - это фиксация объектов, транспортных средств и следов их движения на проезжей части дороги. Второй этап - это детальный осмотр отдельных объектов, включающих транспортные средства, потерпевших и т. д. [2]. Второй этап не связан с блокированием транспортного потока, поскольку осмотр объектов может производиться после их эвакуации с проезжей части дороги. В работе [2] отмечается, что основное время первого этапа расходуется на проведение измерений на проезжей части дороги. В зависимости от сложности ДТП и количества участвующих в нем транспортных средств или пешеходовсреднее количество измерений на проезжей части составляет от 12 до 26, на что уходит в среднем 25-40 минут [2]. Вполне очевидно, что это время может быть существенно сокращено, если для фиксации обстановки ДТП применять стерео- и монофотограмметрические методы фиксации обстановки места происшествия [2].

В работах $[3,4,5]$ описаны возможности лазерного сканирования и использования систем 3D-моделирования при анализе механизма ДТП. При этом автором [4] указано, что такой вид запечатления вещной обстановки на месте происшествия не может являться полностью объективным, хотя разработчики утверждают обратное. В качестве более перспективного варианта автор [4] указывает на способ съемки с использованием беспилотного летального аппарата (БПЛА). Аналогичный подход продемонстрирован и в работе [5]. В работе [6] авторами приведен пример использования съемки с БПЛА в целях уточнения механизма дорожно-транспортного происшествия.

Целью данной работы является разработка научно обоснованного метода использования БПЛА при осмотре места дорожно-транспортного происшествия.

Исходя из этого, были поставлены следующие задачи исследования:

- на конкретных примерах показать, что использование БПЛА при осмотре места дорожно-транспортного происшествия дает более наглядную и объективную информацию;

- проиллюстрировать, что использование БПЛА для осмотра места дорожно-транспортного происшествия требует меньших затрат по сравнению с другими методами; 
- подтвердить, что использование БПЛА для осмотра места дорожно-транспортного происшествия дает более точные исходные данные для последующего проведения автотехнической экспертизы.

\section{Материалы и методы исследования}

Исследования проводились в Центре превосходства «Veritas» Восточно-Казахстанского технического университета им. Д.Серикбаева.

Для построения цифровой модели местности и цифровых моделей транспортных средств используется программное обеспечение Agisoft PhotoScan, установленное на ноутбук (Core I7 8-9 поколения, DDR4 16 Гб 2400 МГц, видеокарта не ниже GeForce GTX 1050, SSD 1 Tб) или стационарный компьютер, БПЛА с возможностью проведения фотосъёмки и пространственной привязки фотоснимков с помощью спутников глобального позиционирования, такие как DJI Mavic 2 Рrо или DJI Phantom 4 Pro+ V2.0.

\section{Результаты и их обсуждение}

На рис. 1 представлено отображение места дорожно-транспортного происшествия в виде схемы ДТП, фотографии и размерной схемы ГИС «Спутник».

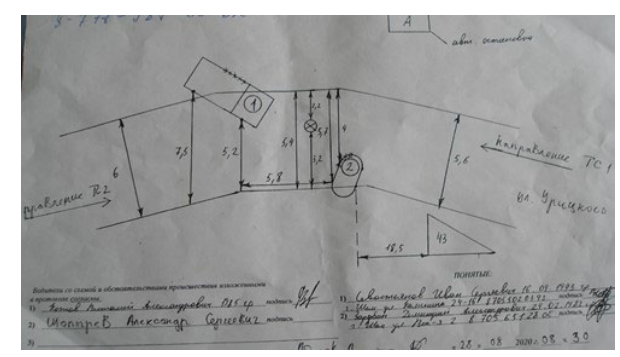

a)

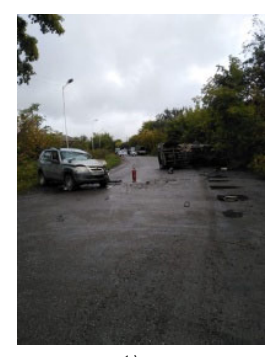

б)

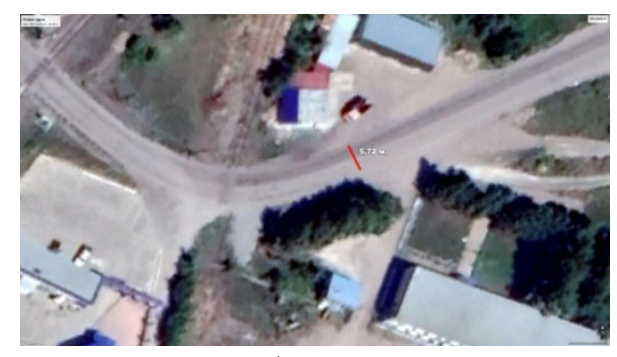

в)

Рис. 1. Отображение места дорожно-транспортного происшествия в виде: a) схемы ДТП; б) фотографии; в) размерной схемы ГИС «Спутник»

Как следует из рис.1а и 1в восприятие информации совершенно разное, вплоть до направления закругления дороги. Кроме того, на обычной схеме указано ДТП два размера ширины проезжей части дороги -5,6 м. и 6 м. На размерной схеме ГИС «Спутник» ширина проезжей части дороги определяется равной 5,72 м. Указанное обстоятельство может быть объяснено и неперпендикулярностью измерительной рулетки к касательной закругления дороги. Поскольку произошло встречное столкновение и одно из транспортных средств выехало на встречную полосу, то разброс 6,0-5,6=0,4 м. имеет существенное значение при определении координат места столкновения.

В работах $[7,8]$ отмечается, что в последние годы ряд организаций начинают использовать материалы фотосъемок с БПЛА, поскольку этот вид обладает множеством преимуществ по сравнению с получением данных с помощью 
космических спутников и воздушных пилотируемых аппаратов. Основные предпосылки использования материалов БПЛА - оперативность получения фотоснимков, возможность съемки с небольших высот, а также в зонах чрезвычайных ситуаций без риска для жизни и здоровья пилотов $[7,8]$.

Одним из видов съемки с БПЛА является использование масштабной ленты (рис. 2).
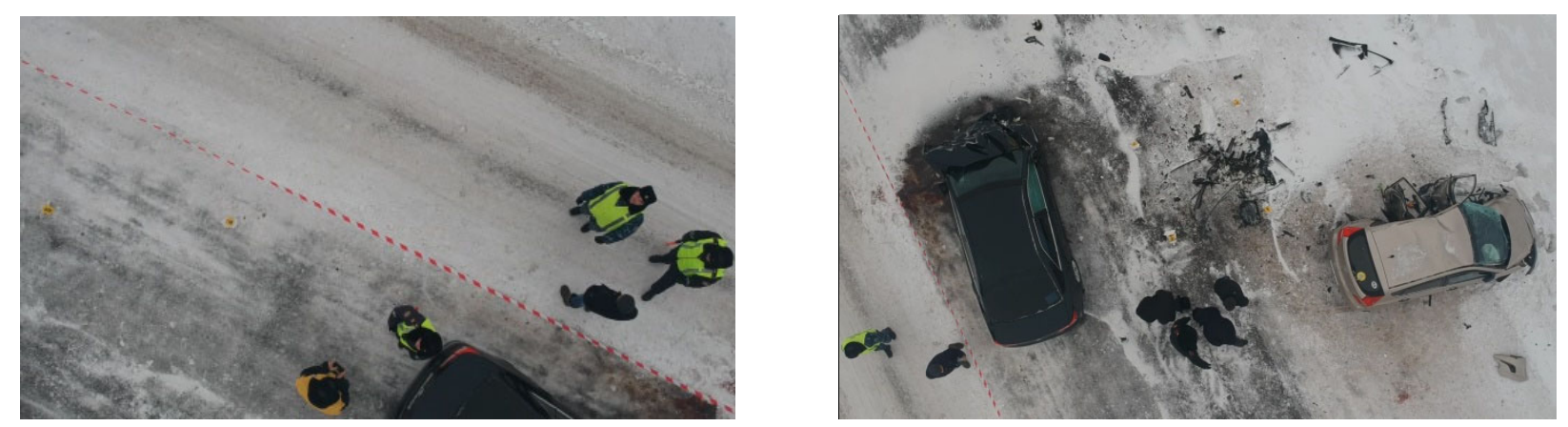

Рис. 2. Съемка с БПЛА с использованием масштабной ленты

Следует напомнить, что в работе [1] указывается, что в соответствии с законами центрального проектирования, по которым строится изображение местности, аэроснимок содержит ряд искажений, величины которых определяются углом наклона оптической оси аэрофотоаппарата и колебанием рельефа местности. Устранение этих искажений осуществляется в процессе их компьютерной фотограмметрической обработки, и в частности - фотографического или цифрового преобразования, называемого трансформированием. В связи с этим использование аэроснимков без их предварительного трансформирования для картографического (топографического) обеспечения выполняемых работ, в том числе в качестве основы ГИС, ограничивается влиянием указанных искажений [1]. Пример использования аэроснимка с масштабной линейкой длиной 4 м. без предварительной обработки приведен на рис. 3.

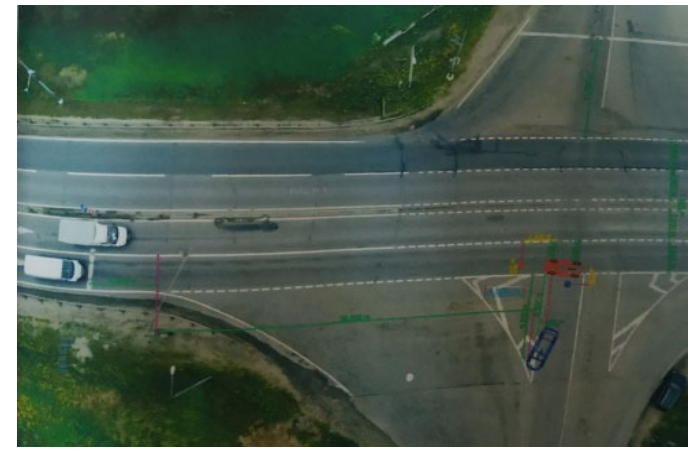

a)

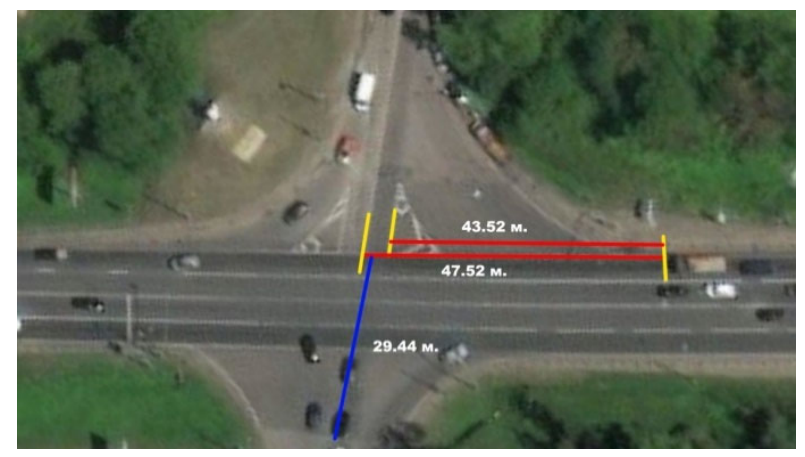

б)

Рис. 3. Отображение места дорожно-транспортного происшествия в виде:

a) снимка с БПЛА без предварительной обработки; б) размерной схемы ГИС «Спутник» 
Как видно из сравнения рис.3а и 3б, первый снимок не ориентирован относительно сторон света, что затрудняет восприятие информации, поскольку он перевернут (направляющие островки дорожной разметки должны быть в верхней части). Также отличаются и размеры, что имеет значение при исследовании механизма ДТП. Искажения на рис.За видны даже по контурам транспортных средств.

Необходимо указать, что в работе [9] производится сравнение воздушного лазерного сканирования (ВЛС) и съемки с БПЛА. Автор [9] приходит к выводу, что ВЛС имеет определенные преимущества, в частности в лесу при ВЛС можно увидеть поверхность, а также несопоставимую производительность, например, за день можно отснять с БПЛА территорию не более 30-50 км., в то время как с использованием ВЛС - до 500 км. Следует отметить, что ДТП не происходят под кронами деревьев и их площадь ограничивается несколькими десятками квадратных метров, поэтому все преимущества ВЛС нивелируются.

В тоже время автором $[10,11]$ указываются следующие преимущества БПЛА:

- возможность выполнения крупномасштабной съемки небольших участков местности при более низкой высоте полета воздушного судна;

- использование более дешевых неметрических камер;

- использование недорогих БПЛА, для которых нет необходимости использования специальных аэродромов для взлета и посадки;

- проведение такой съемки не требует от оператора специальных навыков пилотирования, длительного обучения и лицензии;

- возможность выполнения полета в облачную погоду.

Алгоритм съёмки при фиксации обстановки места ДТП включает выполнение следующих операций $[10,11]$ :

- выбор точки, с которой видны автомобили участников ДТП и объект привязки, расстановка контрольных точек;

- проведение съемки в направлении каждого из участников ДТП;

- проведение съемки в направлении объекта привязки;

- все исходные снимки с БПЛА и запись данных с GNSS приёмника переносятся на персональный компьютер или ноутбук и обрабатываются в программе Agisoft Metashape Pro или Agisoft PhotoScan Pro. В данных программах создаются цифровая модель местности (ЦММ) и цифровая модель рельефа (ЦМР), ортофотоплан, плотное облако точек и 3D модель места ДТП, которые с помощью контрольных точек с миллиметровой точностью позиционируются в пространстве.

По ортофотоплану возможно определение любых размеров (рис. 4).

Следует отметить, что использование съёмки с БПЛА позволяет обеспечить:

- полноту и объективность, основанную на методе фиксации;

- скорость - фиксация обстановки места ДТП окончена сразу же после фотографирования, а не после составления схемы;

- минимизация времени пребывания сотрудников полиции на проезжей части. 


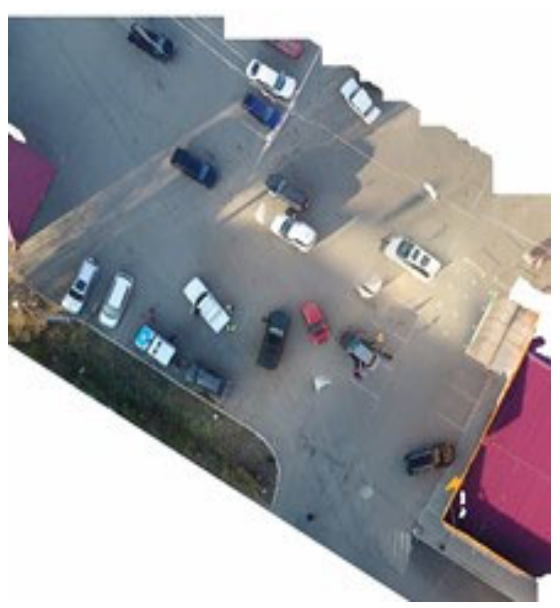

a)

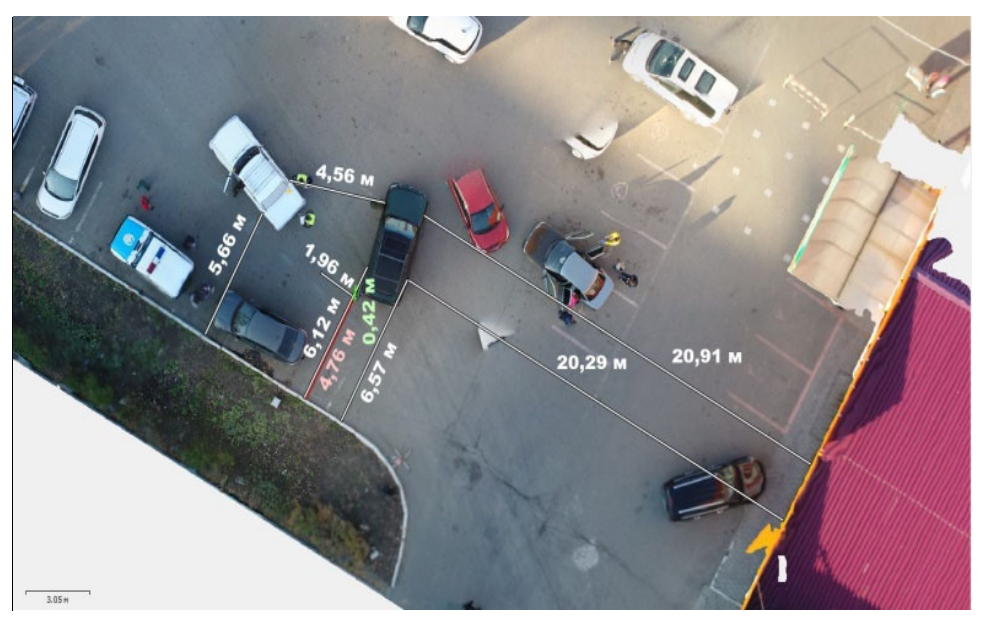

б)

Рис. 4. Осмотр места дорожно-транспортного происшествия:

а) ортофотоплан; б) размерная цепь

Кроме этого, неоспоримым преимуществом данного комплекса является возможность максимально точной фиксации всех повреждений на транспортных средствах, образовавшихся в результате ДТП, что необходимо как для проведения транспортно-трасологической экспертизы, так и для оценки ущерба.

В работах $[10,11]$ отмечается, что преимуществом методики съемки с БПЛА является относительно невысокая стоимость выполнения работ. Также в работах $[7,8]$ отмечается, что точность полученной цифровой модели (облака точек) по выбранным материалам аэрофотосъемки средствами Agisoft PhotoScan соответствует требованиям нормативного документа. Полученная размерная цепь участка ДТП послужит исходными данными для проведения автотехнической экспертизы.

Нет необходимости уточнять, что достоверные исходные данные обеспечивают точность и обоснованность выводов экспертизы.

\section{Заключение}

На конкретных примерах показано, что использование БПЛА при осмотре места дорожно-транспортного происшествия дает более наглядную и объективную информацию по сравнению с другими методами.

Показано, что использование БПЛА для осмотра места дорожно-транспортного происшествия требует меньших затрат по сравнению с другими методами.

Подтверждено, что использование БПЛА для осмотра места дорожно-транспортного происшествия не только сокращает время следственного действия, снижает риск заторов на улично-дорожной сети, но дает более точные исходные данные для последующего проведения автотехнической экспертизы. 


\section{БИБЛИОГРАФИЧЕСКИЙ СПИСОК}

1. Краснопевцев Б.В. Фотограмметрия. - М.: УПП "Репрография" МИИГАиК, 2008. - 160 с.

2. Бондаренко А. А. Применение фотограмметрических методов для фиксации обстановки дорожно-транспортного происшествия // Судебная экспертиза научно-практический журнал. 2005. №3. - С 36-38.

3. Сараев А. В., Данец С.В. Методы исследования дорожно-транспортных происшествий с использованием современных автоматизированных средств // Наука и техника. 2019. Т. 18, № 3. - C. 256-264. https://doi.org/10.21122/2227-1031-2019-18-3-256-264.

4. Думнов С.Н. К вопросу о применении метода лазерного 3D-сканирования при производстве судебной автотехнической экспертизы/Вестник Восточно-Сибирского института МВД России. 2019. Т.90. №3. - С.133-145.

5. Добромиров В.Н., Евтюков С.С.. Голов Е.В. Современные технологии первичного осмотра места дорожно-транспортного происшествия//Вестник гражданских инженеров. 2017. №2 (61). - С. 232-239.

6. Недобитков А. И., Охотенко А. И. Использование Agisoft PhotoScan и беспилотного летательного аппарата в целях установления обстоятельств дорожно-транспортных происшествий.//Вестник КазГЮИУ. 2020. №1 (45). - С.130-137.

7. Хлебникова Т. А., Опритова О. А. Экспериментальные исследования технологии моделирования геопространства по материалам аэрофотосъемки. // Интерэкспо ГЕО-Сибирь-2016. XII Междунар. науч. конгр. : Междунар. науч. конф. «Дистанционные методы зондирования Земли и фотограмметрия, мониторинг окружающей среды, геоэкология» : сб. материалов в 2 т. (Новосибирск, 18-22 апреля 2016 г.). - Новосибирск : СГУГиТ, 2016. Т. 1. -С. 16-20.

8. Хлебникова Т. А., Опритова О. А. Экспериментальные исследования современных программных продуктов для моделирование геопространства по материалам БПЛА. // Интерэкспо ГЕО-Сибирь-2017. XIII Междунар. науч. конгр. : Междунар. науч. конф. «Дистанционные методы зондирования Земли и фотограмметрия, мониторинг окружающей среды, геоэкология» : сб. материалов в 2 т. - Новосибирск : СГУГиТ, 2017. Т. 1. - С. 3-5.

9. Рыльский И.А.Оценка возможности использования данных ВЛС и аэрофотосъемки с БПЛА для обеспечения проектных работ//Геопрофи. 2017. №2. - С. 15-22.

10. Береговой Д. В., Мустафин М.Г. Методика автоматизированного создания топографического плана на основе съёмки с беспилотного летательного аппарата. // Геодезия и картография. 2018. Т. 79. № 9. - С. 30-36.

11. Береговой, Д. В. Создание топографических планов на основе данных съемки с беспилотного летательного аппарата и автоматизации процесса дешифрования: дис. ... канд. техн. наук. - М. :Спб горный университет, 2018. - 136 с.

(C) А. И. Недобитков, А. И. Охотенко, 2021 